\title{
EVALUATING THE BENEFITS OF PROVIDING ARCHIVED ONLINE LECTURES TO IN-CLASS MATH STUDENTS
}

\author{
Radu C. Cascaval \\ Kethera A. Fogler \\ Gene D. Abrams \\ Robert L. Durham \\ University of Colorado at Colorado Springs
}

\begin{abstract}
The present study examines the impact of a novel online video lecture archiving system on in-class students enrolled in traditional math courses at a mid-sized, primarily undergraduate, university in the West. The archiving system allows in-class students web access to complete video recordings of the actual classroom lectures, and sometimes of lecture notes, shortly after the in-class sessions are completed. The data collection for evaluating the impact of this archiving system was designed through focus groups, and consequently, obtained using a customized web survey. Survey questions targeted areas of potential impact such as: changes in attitudes and behaviors (such as study habits), changes in the dynamics of professor-student relationship, and the overall student performance enhancement. The results indicate that the presence of the archived video lectures and lecture notes adds significant value to the learning process with notable improvements in the perceived student performance and overall experience in the class.
\end{abstract}

\section{KEYWORDS}

Supplemental Instructional Materials, Online Archives, Student Achievement, Performance Assessment

\section{INTRODUCTION}

The past few decades have seen compelling increases in the use of technologies in education in general and the teaching of mathematics in particular. Many such practices can be seen in the literature, from the early use of cable and satellite "narrow-casting" of classes [1], and the use of student centered, computer assisted instruction [2], to the more contemporary practices of blended education and web-based courses $[3,4,5,6]$. The present study introduces a logical and natural extension of these heuristic endeavors by focusing on the use of novel methods of web archiving, such as video recordings, to supplement and/or substitute for in-class presentations of both upper and lower division traditional courses in mathematics.

Since 1998, the MathOnline program at The University of Colorado at Colorado Springs (UCCS) has been successfully offering online archives of several UCCS mathematics courses. These are hybrid courses, with enrollments both in-class and online, and the actual in-class lectures are being streamed live and archived for asynchronous viewing. The primary focus has been delivering math content to remote students who could not attend regular classes at UCCS, such as math-advanced high school students, military personnel, and others. A byproduct of this program was that traditional (in-class) UCCS students were also given access to the archived courses for asynchronous viewing. Preliminary data collected in the past for gauging the impact of the availability of such material to the in-class students has been 
encouragingly positive [3]. In 2005, it was theorized that the archival system would in fact be a valuable teaching aid for both hybrid courses and traditional on-campus mathematics courses. As a consequence, the use of archived lectures was expanded to include traditional courses that were not part of the MathOnline program. For traditional courses, with no remote (online) students, the UCCS Department of Mathematics designed and implemented a novel lecture archiving system, with full video recording of the actual classroom presentation. Since Fall 2005, it began offering archives of video lectures for several non-MathOnline courses (mostly upper level undergraduate and graduate courses), as well as for selected MathOnline courses. As of the end of the academic year 2007-2008, more than thirty courses have been archived and are now available freely on our website http://www.uccs.edu/math/video.

\section{MOTIVATION AND GOALS}

This study analyzes the benefits to UCCS students of providing online video lecture archives of selected math courses. The students enrolled in such courses can access the recording of their most recent lectures within hours of the completion of the class session, and they can also access past lectures from their courses as well as from other related courses, such as prerequisite courses. It was hypothesized that the potential for archived lectures was a largely overlooked and relatively simple resource that would enhance learning for math students. The primary concern of this study was to address the question, "How does access to course lecture archives impact students' learning and performance in the course?"

Prior to launching this targeted study in Spring 2007, several instructors (including the first named author) noted that the offering of video archives provide several benefits toward improving student performance (see also [7, 8]). The benefits are especially evident in advanced undergraduate and beginning graduate courses (which at UCCS are often cross-listed), where students are normally exposed to novel types of thinking and reasoning compared with previous courses. An example is the Mathematical Modeling course, the capstone course for all math majors at UCCS. Here, students are exposed to advanced computational techniques, while theoretical skills learned in previous courses are put to work in modeling real world applications. The archived lectures seem to help students grasp the novel approaches taught in this class, by giving them the opportunity to replay (all or parts of) the lectures in this course as well as in previous courses containing prerequisite concepts. Another example is the Modern Analysis course, where the increased level of abstraction usually marks a significant change from the material presented in previous courses. The availability of the archived lecture materials allowed many students to revisit portions of previous lectures, to clarify concepts discussed in class, and to review the material for upcoming exams. It was also found to be useful for students who had to miss a lecture, allowing such students to remain current with the course material.

Specific goals of our study emerged during focus groups conducted in April 2007. Two groups of students, one for lower division courses and one for upper division courses were asked for their perceptions of the archived lectures. The focus group sessions were conducted without direct participation of any math faculty, and the discussions were compiled and kept anonymously from the principal investigators in the Math department, so that students would not be inhibited to express their true opinions about all aspects of the archiving system. Based on these discussions, the web survey questions (described below) were designed.

One deciding factor in initiating this evaluation has been the observation that few universities have embraced similar technologies in their regularly offered math courses. A search on the web indicates that, as of Spring 2007, several other universities offer free course archives, but the math offering in such archives is very limited. Notable examples are Stanford University, University of California at Berkeley, MIT, and Yale University. Some universities have created online archives specifically for math courses, 
Evaluating the Benefits of Providing Archived Online Lectures to In-class Math Students

such as North Carolina State University; however, unlike our approach, the format of the classroom being archived seems to have been altered to accommodate the archiving tools. It is important to mention at this point that the UCCS Math archiving system has been deployed with minimum disruption to the traditional classroom setting via whiteboard lectures and hand-written notes. This system, we believe, allows for a better assessment of the benefits of the archives to student learning without any compromise to the otherwise essential classroom student-teacher interaction. Consequently, the present study relies on a traditional classroom format with essentially no change to teaching heuristics and methods.

\section{PROGRAM DESCRIPTION}

The UCCS archiving system is comprised of two distinct archival methods, both designed to offer web access to lectures, either synchronously, primarily for remote students, or asynchronously, shortly after they are delivered in class, for the in-class students and remote students (if any). Since this study focuses on the in-class population, we will emphasize the asynchronous aspects of these methods.

The first method, used primarily for hybrid courses since 1998, requires a smart classroom (with a permanently installed LCD projector), and consists of a screen capture system (currently iLinc), in which the instructor utilizes an input device such as a Wacom tablet or a tablet PC. The computer screen is projected on a large, front-of-classroom screen, so in-class students can see the instructor's screen. In addition, the image with audio is simultaneously captured, streamed live and later archived. Depending on the frames per second (fps) rate and the audio compression settings, the file size can reach as little as 10 $\mathrm{MB} / 1$ hour of lecture, making it suitable for downloads over dial-up/modem connections.

The second archiving method, introduced in Fall 2005 for both hybrid and traditional courses, consists of videotaping a regular classroom presentation, then compressing it using QuickTime broadcaster in H.264 format (640x360 widescreen) with $15 \mathrm{fps}$ rate and $450 \mathrm{key}$ frame rate. The data bit rate is limited to $400 \mathrm{kbs}$ and frame reordering is enabled. The actual compression rarely exceeds $200 \mathrm{kbs}$, and achieves a good video quality, thus resulting in a relatively small file size $(\sim 100 \mathrm{MB} / 1$ hour of lecture), suitable for downloads over high-speed (Cable/DSL) Internet connections. The compression can be done either live, whenever the camera can be connected to a computer during the lecture, or after the lecture. Time of compression is 1XT. Post-processing is minimal and can be done within minutes using QuickTime Pro software. The instructor can use the usual chalkboard, or, if the room setup includes a LCD projector, can use an electronic input device (such as a tablet PC), in which case lecture notes can be made available immediately after class.

The main cost incurred in creating the video or iLinc lectures for a course consists of hourly wages, usually at the student worker rate, for monitoring the recording (audio/video) session. Post processing and organizing the web archive requires minimal work and can be accomplished within minutes from the end of the actual lecture.

It is important to emphasize that archiving methods do not change the classroom format, and that the presence of the archiving tools is not intrusive. As our survey indicates, in-class students are able to ignore the added features and concentrate on the in-class presentation, as they would in any other traditional classroom. The population of interest in the present study was restricted to in-class students, who only use the archives asynchronously, but it is worth noting that both methods of archiving also allow for synchronous viewing, with the latter method offering remote students the choice of participating interactively. Such interactions would also be recorded for subsequent asynchronous viewing and would become part of the archives that student could watch. 
Throughout the semester, the archived materials for each course (video, iLinc and/or notes) were uploaded, organized and posted on a webpage, where students can go (upon free registration) to access them. One course (Calculus III) also featured podcasting and RSS feeds on an experimental basis, mostly for convenience.

\section{METHOD}

\section{A. Participants}

All students enrolled in seven Math courses during Spring 2007 were initially contacted by e-mail about participating in the survey. Three courses were hybrid (MathOnline) undergraduate courses (Calculus II, Calculus III, Number Theory) and used the iLinc method of archiving lectures. One of these hybrid courses offered full video format in addition to the iLinc recording. The remaining four courses were traditional math courses offered at the senior undergraduate/beginning graduate level (Mathematical Modeling, Modern Analysis II, Scientific Computation and Mathematical Statistics II) and used the video archiving method. Two of these traditional courses also offered lecture notes archiving in addition to the video lectures. A total of six instructors taught the seven courses considered in this study.

The total cumulative enrollment for the seven courses featuring the archiving system was 158 , with only 11 (upper division) students being enrolled in two courses simultaneously. Hence only 147 email invitations to participate in the survey were sent out. As part of the recruitment effort, potential participants were advised that a $\$ 20$ bookstore certificate would be awarded to three randomly selected students who completed the survey.

Of the 147 students contacted, 51 completed the survey. Participants were asked to complete the Archived Math Survey basing their responses on the archived class for which they were enrolled in the spring semester of 2007. Students who were enrolled in more than one course being archived were asked to pick one of the courses they were enrolled in and answer all survey questions based on that course. Of the students who responded to our survey, $25 \%$ were enrolled in a mathematics course with full videorecordings, $51 \%$ - with iLinc presentation, and 20\% - both video and iLinc; $4 \%$ did not respond. Of the participants, $59 \%$ were male and 37\% were female (4\% of participants did not report their gender). Participants consisted of 39\% math majors, 57\% non-math majors (i.e., Engineering, Biology, Computer Science, Physics, Chemistry, Other), and 4\% did not report their major.

\section{B. Materials}

In addition to demographic information, participants' usage of and satisfaction with the mathematics archival system was assessed using a 20-item scale (see Appendix A) that included items designed to assess attitudes (e.g., I like being able to revisit the material in the archives repeatedly), behaviors (e.g., I use the archived lectures to verify what my professor has said), and ease of using the system (e.g., I am distracted by the recording procedures). Responses were measured on an 8-point Likert scale from 1 (strongly disagree) to 8 (strongly agree); four items were reverse-scored.

\section{Procedure}

Students who were enrolled in an archived mathematics course in the spring semester of 2007 were emailed an invitation to participate in an online survey assessing their attitudes toward and usage of the system. A link was supplied in the email that redirected them to a site containing an informed consent 
Evaluating the Benefits of Providing Archived Online Lectures to In-class Math Students

form, a 40-item survey, and demographic questions. Only those who chose 'I agree to participate' proceeded to the survey and demographic questions; those who did not agree to participate were directed to a page thanking them and redirecting them to the mathematics department website. Fifty-nine students responded and eight declined to participate.

A reliability assessment was conducted on the 40-item scale revealing a Cronbach's alpha coefficient of .83. As an exploratory procedure, a principal components factor analysis was conducted on the 40 items, forcing a single component solution, revealing an eigenvalue explaining $15 \%$ of the variance. Using the results of this analysis and the Cronbach's alpha analysis, we removed twenty of the items, resulting in a unidimensional scale accounting for slightly over $40 \%$ of the variance and a Cronbach's alpha of .92. Table 1 depicts the item correlations, Cronbach's alpha if the item was deleted, and the factor loadings.

\section{RESULTS}

Twenty Likert questions assessed the participant's satisfaction and usage of the archived mathematics system using an 8-point response scale. Low scores indicate a negative experience or attitude and high scores indicate satisfaction and positive experiences in using the system (four items were reverse scored, see Appendix A). Preliminary analyses were performed to ensure there were no violations of normality, linearity and homoscedasticity. One-Sample t-tests were conducted on each item as well as on the overall scale mean to determine if there were significant differences between the participant's responses and the mid-point of the scale, 4.5 , which would indicate neither satisfaction, nor dissatisfaction with the archival system. The overall mean, $(M=5.81, S D=1.17)$ was significantly different from $4.5, t(50)=7.98, p<$ .01 , and indicates that participants rated the archives positively, as indicated by a mean significantly higher than the disagree-agree scale midpoint (see Table 1). Responses per item also indicate significantly higher-than-average satisfaction scores for all items except two, for which responses were consistent with neither liking nor disliking the archival system.

A one-way ANOVA was conducted to determine if there were differences in overall satisfaction of the archival system between males $(M=5.63, S D=1.26)$ and females $(M=6.10, S D=.98)$. There were no significant differences found, $F(1,48)=1.54, p>.05$. A one-way ANOVA was also conducted on overall satisfaction of the archival system and whether the participant was a mathematics major $(M=$ $5.83, S D=1.37)$ or a non-mathematics major $(M=5.78, S D=1.03)$. No significant differences were found between these groups, $F(1,48)=0.02, p>.05$.

The relationship between overall satisfaction with the archival system and the grade each participant received in the archived class for which he or she was responding was investigated using a one-way ANOVA with four levels (grade received: A, B, C, D/F). There were no significant differences between groups, $F(3,48)=1.36, p>.05$. Therefore, the grade a participant received did not significantly impact satisfaction with the archived system.

The relationships between overall satisfaction of the archived system, age, and number of math classes taken were investigated using Pearson product-moment correlation coefficient. There were no relationships found between the three variables, indicating that neither the participant's age $(r=-.107, n=$ $51, p>.05)$, nor the number of math classes taken $(r=-.11, n=51, p>.05)$ had an impact on overall satisfaction with the archival system.

Significant correlations were found between total satisfaction with the archived system and the overall difficulty of the class $(r=-.28)$, the grade received $(r=.28)$, and the grade expected had the class not 
been archived $(r=-.28)$. This indicates convergent validity: the more difficult the class was perceived to be, the more positively respondents rated the archived system; the higher the grade received, the more satisfied the respondents were with the archived system; and the higher the total satisfaction rating, the lower the expected grade had the class been offered without access to the archived system.

Table 1. Item Analysis and Internal Reliability for the Spring 2007 Math Survey $(N=51)$

\begin{tabular}{|c|c|c|c|c|c|}
\hline Item & $M$ & $S D$ & $r$ & $\begin{array}{l}\text { without } \\
\text { item }\end{array}$ & $\begin{array}{l}\text { factor } \\
\text { loading }\end{array}$ \\
\hline 1. I like being able to revisit the material in the archives repeatedly. & $6.39 *$ & 1.96 & .76 & .91 & .81 \\
\hline 2. I use the archived lectures to help with homework. & $5.63^{*}$ & 2.38 & .60 & .91 & .67 \\
\hline 3. I think the image quality of the archived lectures is good. & $5.65^{*}$ & 1.43 & .48 & .92 & .52 \\
\hline 4. The archives help me understand complex concepts. & $5.63^{*}$ & 1.78 & .61 & .91 & .70 \\
\hline 5. I use the archived lectures to verify what my professor has said. & $5.45^{*}$ & 2.08 & .51 & .92 & .40 \\
\hline 6. I use the archived lecture to review for exams. & $5.78^{*}$ & 1.90 & .71 & .91 & .57 \\
\hline $\begin{array}{l}\text { 7. I can listen more in my archived class(es) than in my non-archived } \\
\text { classes. }\end{array}$ & 4.22 & 2.11 & .53 & .92 & .76 \\
\hline 8. I use the archives to supplement study. & $5.43 *$ & 2.00 & .62 & .91 & .60 \\
\hline $\begin{array}{l}\text { 9. I like the archived lectures because I can skip material I already } \\
\text { understand. }\end{array}$ & $5.22 *$ & 2.00 & .37 & .92 & .67 \\
\hline $\begin{array}{l}\text { 10. I like the idea of being able to see both the professor and what is } \\
\text { being written. }\end{array}$ & $6.04 *$ & 1.70 & .41 & .92 & .43 \\
\hline $\begin{array}{l}\text { 11. Given a choice between a section of a class with archived lectures } \\
\text { or without, I would choose the archived section. }\end{array}$ & $6.22 *$ & 2.00 & .70 & .91 & .44 \\
\hline $\begin{array}{l}\text { 12. The archives are useful to me for providing information missed } \\
\text { in class. }\end{array}$ & $6.69^{*}$ & 1.29 & .55 & .92 & .74 \\
\hline 13. I think all my math classes should be archived. & $6.69^{*}$ & 1.64 & .64 & .91 & .59 \\
\hline 14. I like being able to hear the material repeatedly in the archives. & $5.94^{*}$ & 1.99 & .82 & .91 & .69 \\
\hline $\begin{array}{l}\text { 15. I spend more time studying when archived lectures are available, } \\
\text { than when they are not. }\end{array}$ & 4.51 & 2.27 & .67 & .91 & .86 \\
\hline $\begin{array}{l}\text { 16. I have learned more than I would have had I not had access to the } \\
\text { archived lectures. }\end{array}$ & $5.82 *$ & 1.89 & .61 & .91 & .72 \\
\hline $\begin{array}{l}\text { 17. If I didn't get the concept in class, seeing the same presentation } \\
\text { again doesn't help. (R) }\end{array}$ & $6.16^{*}$ & 1.62 & .46 & .92 & .66 \\
\hline 18. I would rather borrow notes from someone than use the $\operatorname{archives}(\mathrm{R})$ & $6.45^{*}$ & 1.78 & .49 & .92 & .60 \\
\hline 19. I am distracted by the recording procedures. (R) & $7.06^{*}$ & 1.35 & .38 & .92 & .54 \\
\hline 20. It is difficult for me to pay attention to the archived lectures. (R) & $5.16^{*}$ & 1.83 & .55 & .91 & .49 \\
\hline
\end{tabular}

* Significantly different from the scale mid-point of 4.5 at an alpha level of .05; (R) Reverse scored items.

In addition to the survey questions above, participants were asked to supply (voluntarily) the grade received in this class. Of the respondents, $27 \%$ received an $\mathrm{A}, 31 \%$ received a $\mathrm{B}, 18 \%$ received a $\mathrm{C}$, and $20 \%$ received a D or lower. $4 \%$ of participants did not supply their grade. A majority of participants $(84 \%)$ rated their class as difficult to very difficult, and $51 \%$ of the respondents believed that their grade would have been lower had the class not been archived. 
A subsequent analysis of the use of the archives was conducted using the number of accesses stored by the server. For the upper division courses, where the total enrollment was 59 enrolled students (out of the 149 invited to participate), this analysis revealed that all (100\%) of these upper division students visited their respective course archives at least once during the semester, and they visited the archives on average 15.4 times during the semester. No data was collected on how many video lectures these students downloaded or watched during each visit, but it is plausible that they accessed more than one lecture. Also, no data was collected of the time during the semester the visits occurred, but anecdotal evidence indicated that the archived lectures were more in demand prior to exams or quizzes. This evidence is based, for example, on the number of complaints received right before an exam, complaints generated by instances when the server was slower in serving the lectures, or when certain lectures were posted with some delay. Similar data was collected for one of the lower division courses (Multivariable Calculus), revealing a somewhat different usage pattern. Out of the 35 students who completed the class, only 24 of them (or 68\%) utilized the web archive at least once in the semester, with an average visit count of 14.58 times per student.

The figure below illustrates data collected for two representative courses (Multivariable Calculus and Mathematical Modeling courses), which had the highest enrollment in each of the division and which were taught by the same instructor. Individual grades are plotted against the usage during the semester for all students enrolled in both courses.

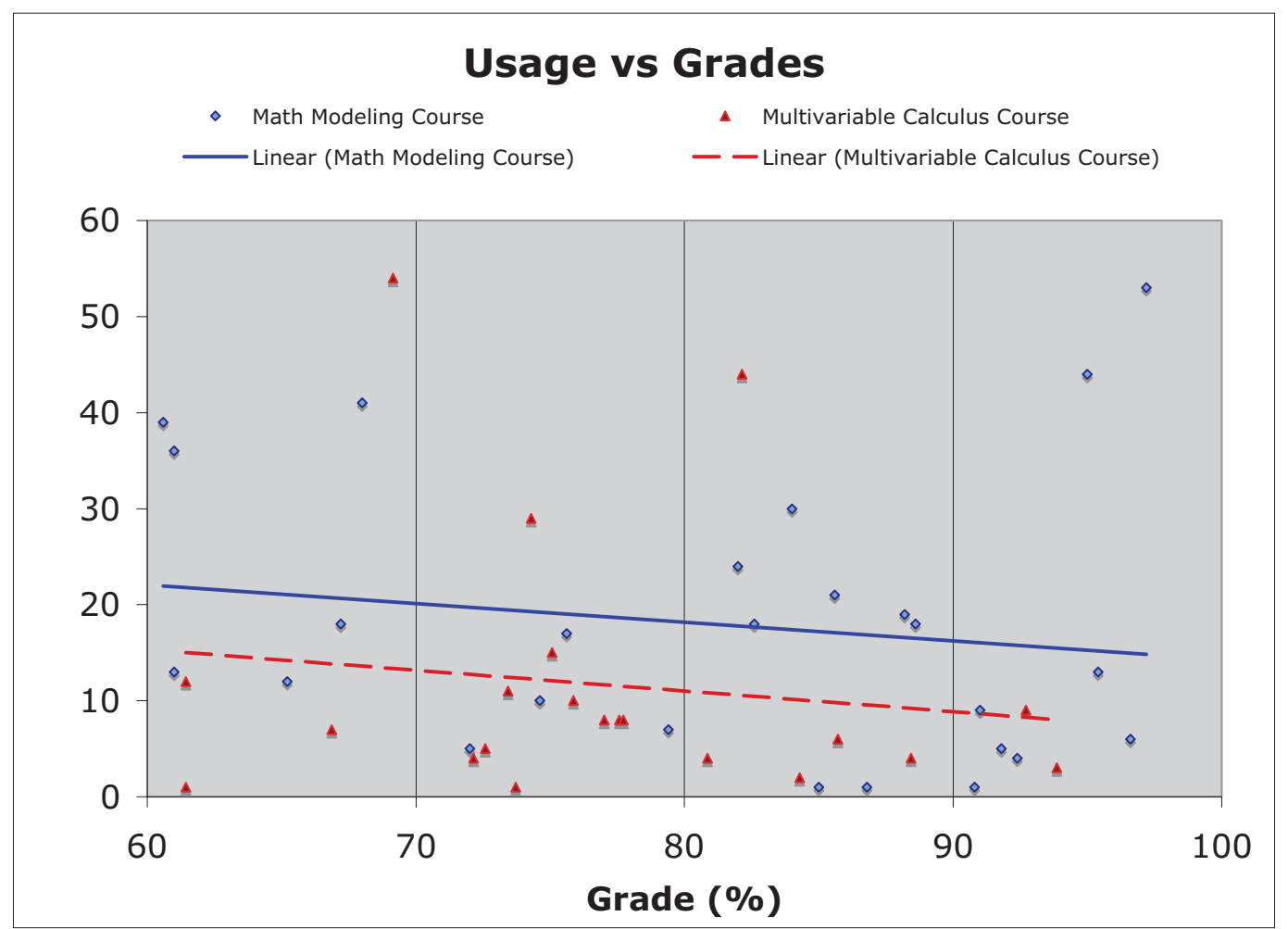

Figure 1. Data Representing the Usage (Number of Hits) for Each Student Who Completed at Least $60 \%$ of the Work Vs Their Grades (\%) in the Course. Two Representative Courses are Illustrated, One Lower Division (Multivariable Calculus, Enrollment = 34) and One Upper Division (Math Modeling, Enrollment = 29).

A regression line for each set of data reveals a similar pattern for both courses, with slightly higher usage among students who received a lower score in the course versus students who received a higher score. It is also worth noting the higher overall usage in the upper division class (regression line shifted upward) 
versus the lower division class, which could indicate the difficulty level of the class and the presumptive higher overall utilization of the archives in such courses. Since the actual responders to the survey remained anonymous to the principal investigators of this study, it has been impossible to isolate only the data indicating the usage of the archives among the actual responders to the survey. It is only from the grades reported (voluntarily) by the survey participants that one could draw conclusions as to whether only students who used the archive more heavily actually chose to respond to the survey or not. Despite the intrinsic value of such conclusions, the authors decided to leave this kind of analysis as the subject of a future study.

\section{DISCUSSION}

The online archiving of university level courses seems still in its infancy, especially in technical fields such as mathematics, where the traditional classroom setting seems to be the most widely used method of instruction. Online archiving has already proven to be an emerging learning tool, essential in the diverse student community of universities such as UCCS, and its benefits are not limited to distance learning. Informal observations on the beneficial aspects of this archiving process, made by instructors in courses that offered it in the past, have been confirmed in this formal study.

This study focused on the impact of the course lecture archives on students' learning and performance in the course. The data was collected from students enrolled in several courses, with different level of difficulty (both lower division and upper division) and taught by several instructors. The cumulative data indicates that the presence of the archived video lectures and lecture notes adds significant value to the learning process with notable improvements in the perceived student performance and overall experience in the class. This conclusion seems to hold true regardless of the course level and of the particular teaching style of the instructor.

We envision that archiving will soon be a standard tool that universities will be expected to showcase to successfully attract and retain students, and that further studies such as ours will prove to be instrumental in administrative decisions to implement this on a larger scale at many universities. In our limited deployment of the video archiving system, it has already been documented that instructors can accommodate such technologies with minimum or no effort and that more and more instructors are willing to embark on this enterprise, in order to provide students with supplemental materials that prove to be useful to a majority (if not all) of their students. Several techniques of maintaining or even improving attendance have been suggested, such as administering frequent in-class quizzes or delaying the posting of the archived lectures. In the courses relevant to this study, the attendance did not seem to be affected by the presence of our archiving system, indicating that there were no significant negative changes in student attitudes and behaviors. Our experience showed that a drop in attendance due to the presence of archived lectures was not a major reason of concern but that the instructors themselves can easily implement such measures if needed. Nevertheless, a more careful analysis of this aspect should be conducted in future studies. At the same time, further studies into the effects of this new technology on enrollment and retention rates would support the broader implementation of such archiving systems.

While the investigators are striving to optimize the efficacy of the archived process and assessment tools, it is already our belief that studies such as ours are at the forefront of research in teaching and learning. We anticipate that the results of the present study are relevant to other disciplines and other university communities interested in openly sharing their knowledge via the web. The results of this study may encourage other math departments to adopt similar technology and share their courses online with other universities. This open cooperation between departments in the same field of study would be especially advantageous to those with limited course offerings, particularly in small graduate and Ph.D. programs. 
Because of the low cost nature of the video technology involved, other departments may find it perfectly suitable for their regularly offered courses (such as in humanities, science and engineering fields). This in turn will likely create the demand for the infrastructure needed to support individual departments within a larger scale deployment of this technology throughout the university campus.

The overwhelmingly positive feedback from students with no differences detected for the demographic variables of interests of study, ages, and gender indicate that the archival system employed in the present study, and those that are similarly designed, have universal appeal and effectiveness as an educational supplement.

\section{ACKNOWLEDGEMENT}

The authors acknowledge the support of the 2006-2007 University of Colorado President's Teaching and Learning Collaborative (PTLC) and the UCCS Student Achievement Assessment Committee (SAAC). The authors express their gratitude to the external reviewers for the comments that helped improve the exposition of this article.

\section{REFERENCES}

1. Kenworthy, B. Educational broadcasting - just for kids? Australian Journal of Educational Technology 5(1): 47-55, 1989.

2. Cotton, K. Computer-Assisted Instruction. School Improvement Research Series, Northwest Regional Educational Laboratory, May 1991.

3. Abrams, G. and J. Haefner. Blending online and traditional instruction in the mathematics classroom: A case study. The Technology Source September 2002. http://technologysource.org /article/blending online and traditional instruction in the mathematics classroom/.

4. Dalsgaard, C. and M. Godsk. Transforming traditional lectures into problem-based blended learning: Challenges and experiences. Open Learning 22(1): 29-42, 2007.

5. Garrison, D. R. and H. Kanuka. Blended learning: Uncovering its transformative potential in higher education. Internet and Higher Education 7: 95-105, 2004.

6. Shea, P., C. S. Li \& A. Pickett. A study of teaching presence and student sense of learning community in fully online and web-enhanced college courses. Internet and Higher Education 9: 175190, 2006.

7. Fill, K. and R. Ottewill. Sink or swim: Taking advantage of developments in video streaming. Innovations in Education and Teaching International 43(4): 397-408, 2006.

8. Ginns, P. and R. Ellis. Quality in blended learning: Exploring the relationships between on-line and face-to-face teaching and learning. Internet and Higher Education 10: 53-64, 2007. 


\section{APPENDIX A SPRING 2007 MATHEMATICS ARCHIVED LECTURE WEB SURVEY}

The following statements are designed to assess your opinions regarding the archived math lectures. Please answer for the archived math class you completed in Spring 2007. If you were enrolled in more than one archived math class, choose ONE and ANSWER THE FOLLOWING QUESTIONS FOR THAT CLASS. For each item, please choose the number that corresponds most closely to your opinion. Please read each item carefully, and answer all questions. THERE ARE NO WRONG ANSWERS!

$\begin{array}{llllllll}\begin{array}{l}\text { strongly } \\ \text { disagree }\end{array} & 2 & 3 & 4 & 5 & 6 & 7 & \begin{array}{l}\text { strongly } \\ \text { agree }\end{array}\end{array}$

1. I like being able to revisit the material in the archives repeatedly.

2. I use the archived lectures to help with homework.

3. I think the image quality of the archived lectures is good.

4. The archives help me understand complex concepts.

5. I use the archived lectures to verify what my professor has said.

6. I use the archived lecture to review for exams.

7. I can listen more in my archived class(es) than in my non-archived classes.

8. I use the archives to supplement study.

9. I like the archived lectures because I can skip material I already understand.

10. I like the idea of being able to see both the professor and what is being written.

11. Given a choice between a section of a class with archived lectures or without, I would choose the archived section.

12. The archives are useful to me for providing information missed in class.

13. I think all my math classes should be archived.

14. I like being able to hear the material repeatedly in the archives.

15. I spend more time studying when archived lectures are available, than when they are not.

16. I have learned more than I would have had I not had access to the archived lectures.

17. If I didn't get the concept in class, seeing the same presentation again doesn't help. (R)

18. I would rather borrow notes from someone than use the archives. (R)

19. I am distracted by the recording procedures. (R)

20. It is difficult for me to pay attention to the archived lectures. (R)

(R) Reverse scored item. 